\title{
Design of Metering Device Key Parts of Pneumatic Grass
}

\section{Seeder}

\author{
Zhai Gaixia, Wang Zhenhua, He Gang, Liu Guilin and Yang Li \\ Hohhot Branch of Chinese Academy of Agricultural Mechanization Sciences, Hohhot 010020, China
}

\begin{abstract}
Based on the mechanical and physical properties study of forage grass seeds, multi-line with one-device type metering device was designed. It was composed of adjustable screw, stirrer, metering device housing and central metering sheave and so on. The sowing rate can be set by turning the screw to change the working length of the central metering sheave relative to the metering device housing. The stirrer inside of the sheave housing is used to prevent seeds overhead. And metering of different sizes of seed is adjusted by changing the position of internal components of the slot wheel mechanism. Innovative design on the structure of the central metering sheave was finished. According to the structure parameters and physical characteristic parameters, different seed sowing rate of per hectares was calculated. And then the working length scale of the central metering groove wheel was made. And there is a one-to-one correspondence between scale values and sowing quantity per hectare of different kinds of seed.
\end{abstract}

Key words: Seeder, metering device, central metering sheave, sowing rate.

\section{Introduction}

Metering device is the key working parts of the grass-seed seeding machine, and its performance has direct influences on the planting [1]. The design of the metering device should meet with these requirements. The metering quantity should be very uniformity and come up to advanced world standards. It should have good versatility and large metering quantity adjusting range. And there is no or less damage to the grass seed. Metering device can be divided into mechanical and pneumatic type based on the structure, mainly including horizontal disc type, tilting disc type, greapel wheel type, declined scoop type, inside-filling holes wheel type, vertical revolving scoop, picker finger type, ribbon type and pneumatic type, etc. [2]. Pneumatic type metering device can be divided into the air blowing type and air suction type [3-8]. The pneumatic type metering device has widely application because of its high adaptability and high metering quality [9-11].

Corresponding author: Zhai Gaixia, Ph.D., senior engineer, research fields: farming and animal husbandry machinery engineering. E-mail: zhaigaixia79@163.com.
Grass seeds were discharged by the revolving outside-Geneva with slot on the cylinder of the outside groove wheel metering device. The sowing performance is affected by seed size and shape. The structure of the outside groove wheel metering device is simple, and it is easy to manufacture and use, and is widely applied. It is the critical component of the seeder. In the paper, a kind of central outside Geneva wheel metering equipment which can match with pneumatic conveying type metering device was designed. And based on the analysis results of basic physical properties of grass seed, metering quantity per hectare of different size seed of the pneumatic conveying type metering device was calculated. The sheave working length scale with corresponding value with metering quantity per hectare was made.

\section{Structure and Working Principle}

Structure and parameters of the metering device of grass seeder should be concerned with appearance, seed flow characteristics, suspension characteristics and moisture absorption characteristics and so on. 
According to the seeding problems of grass seed, such as different kind of grass seed has different physical characteristics, and geometry size is different, and grass seed is light and has irregular shape, and based on grass seed sowing process requirements, we design a central outside Geneva wheel metering equipment. When the machine is working, different size and shape seed can be metered normally by adjusting the Geneva mechanism.

\subsection{Metering Device Structure}

Metering device is mainly composed of adjusting screw rod, stirrer, shell body and central metering Geneva and so on [12]. The central metering sheave is the main component of the metering device. It comprises Geneva mechanism, Geneva shell, stirring teeth and regulating mechanism, as shown in Fig. 1. The Geneva mechanism is comprised of Geneva, adjusting plate, variable groove bracket, big gear, variable groove plate, smooth wheel, screw thread adjusting plate, as shown in Fig. 2. When the device is running, land wheel rotates and the power is provided to central metering Geneva by the chain transmission, and then the Geneva is driven to rotate.

When the Geneva dived into seed can rotates, the Geneva groove is filled with seed under the action of gravity. And then seed rotates along with the Geneva. It realizes forced metering. Seed outside of the Geneva forms a driven seed layer under the stirring action of the outer circle of Geneva and friction action between the grains. Metering seed includes seed in the groove and driven layer. The metering quantity is relatively stable. According to the seed suspension characteristic and two-phase flow fluid mechanics characteristics, seed is assigned to each row of pipe to be planted by the pneumatic type distributor. It can realize uniform planting for different kinds of seed grass by the central metering Geneva equipment supporting pneumatic conveyor metering method [13, 14].

The stirring teeth were designed to prevent illiquid seeds overhead in the Geneva wheel casing. When metering small size seeds with awn, the small gear of the stirring teeth engages with the big gear of the Geneva mechanism, so the stirring teeth rotate. And when metering big size seeds without awn, the small gear of the stirring teeth and the big gear of the Geneva mechanism are separated. The assembled location of the stirring teeth saw in Fig. 1.

In conclusion, the central metering groove wheel device has the following characteristics. Firstly, it has a strong adaptability for different size and shape seeds and can be used to seeding different size seeds by adjusting the Geneva mechanism. Secondly, it was driven by the ground wheels, and not affected by machine walking speed, the seeding quantity is uniform. Finally, the structure of the metering quantity adjusting mechanism is simple, convenient and reliable.

\subsection{The Metering Quantity Adjustment of the Different} Size Seeds

Through adjusting the Geneva mechanism, a metering port with different flute profile and a length of $\mathrm{H}$ was formed inside the Geneva shell to meter the seeds. The metering groove shape of $\mathrm{H}$ section is

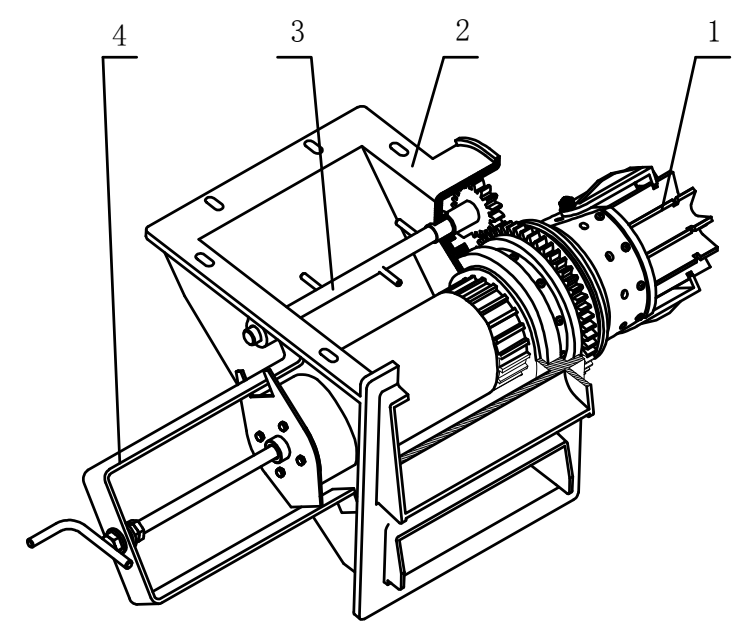

Fig. 1 Central metering groove wheel device structure diagram.

1. Geneva mechanism; 2. Geneva shell; 3. Stirring teeth; 4. Regulating mechanism. 


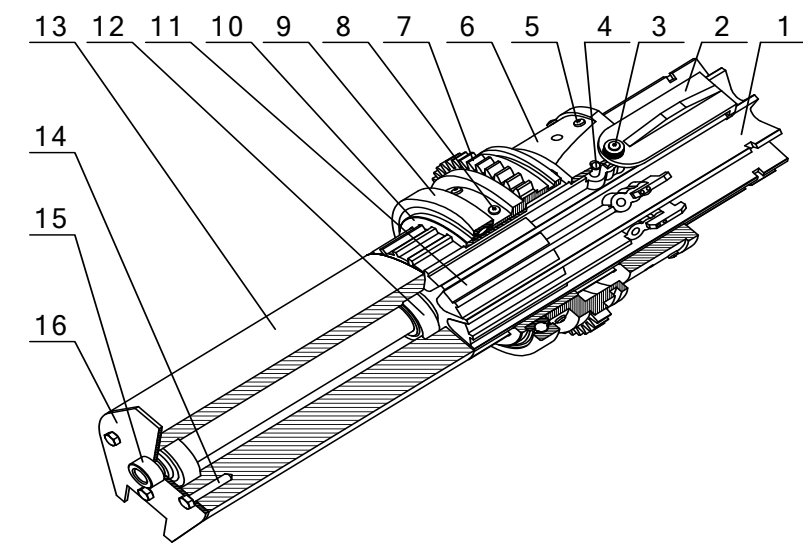

Fig. 2 Geneva mechanism structure diagram.

1. Geneva; 2. Adjusting plate; 3. Long screw; 4. Hinge pin; 5. Screw; 6. Variable groove bracket; 7. Big gear; 8. Short screw; 9. Big bearing; 10. Bearing lining; 11. Variable groove plate; 12. Small bearing; 13. Smooth wheel; 14. Big screw; 15 Nut; 16. Screw thread adjusting plate.

fluted (Fig. 3) while the adjusting-plates engage with the big gear (Fig. 4). At the moment, it is suitable for big seeds sowing. The metering quantity can be adjusted steplessly by rotating the threaded rod of the adjusting mechanism to change the relative positions of the Geneva and Geneva shell, that is, the value of $\mathrm{H}$. The metering groove shape of $\mathrm{H}$ section is the shape of the variable groove plate (Fig. 5) while the adjusting-plates engage with the Geneva (Fig. 6). And at the moment, it is suitable for small seeds sowing.

\subsection{Selection of the Major Parameters}

2.3.1 Diameter, Rotating Speed and Working Length

Geneva wheel diameter is both relevant to rotating speed and working length. When the metering quantity is definite, if the Geneva wheel diameter is oversize, the rotating speed and working length will reduce correspondingly, and it will lead to the intermittent and inequality metering. If the diameter is undersize, the rotating speed must be increased, and then damage rate of the seed will increase. In order to meter both small seed and big seed, according to Ref. [2], the diameter of the Geneva wheel is selected as $100 \mathrm{~mm}$.

The rotating speed range is $9-60 \mathrm{r} / \mathrm{min}$ for the stability of metering quantity each turn. In order to

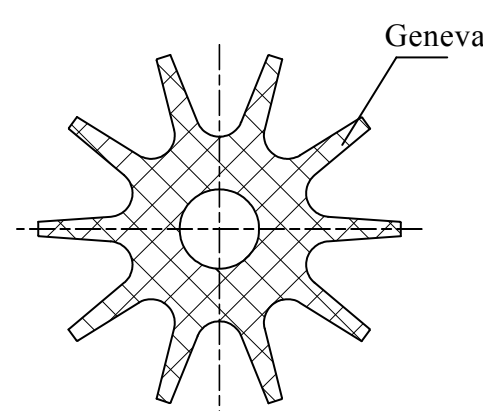

Fig. 3 Groove shape of Geneva wheel for large seed sowing.

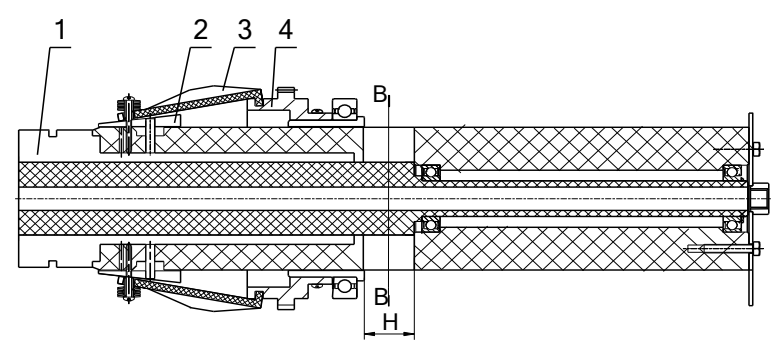

Fig. 4 Geneva mechanism structure diagram for large seed sowing.

1. Geneva; 2. Variable groove bracket; 3. Adjusting plate; 4. Big gear.

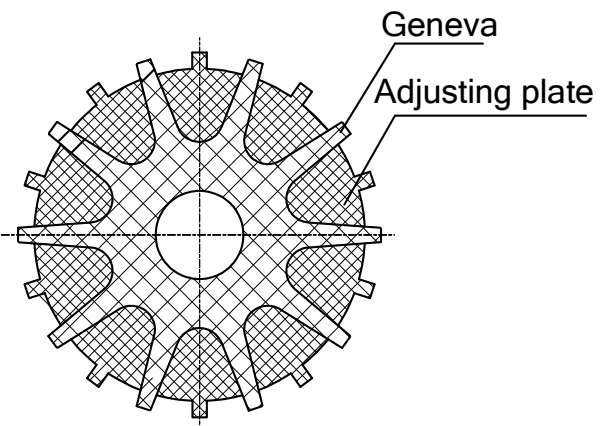

Fig. 5 Groove shape of Geneva wheel for small seed sowing.

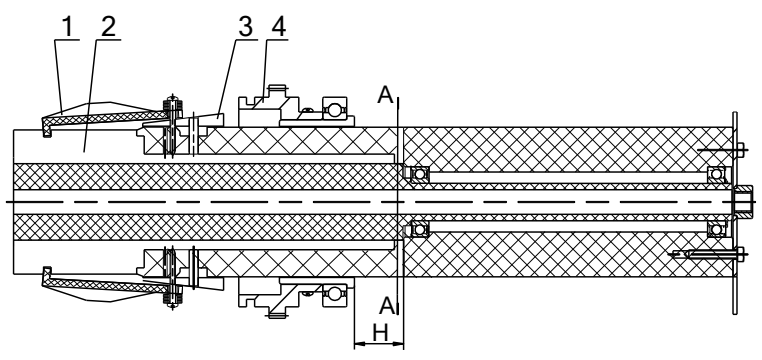

Fig. 6 Geneva mechanism structure diagram for small seed sowing.

1. Geneva; 2. Variable groove bracket; 3 . Adjusting plate; 4. Big gear.

avoid impairing seed flow inside the metering device and affecting the metering uniformity, the working 
length should not be too small. The minimum working length should be greater than 1.5-2 times seed length. To meet with the requirements of high working speed and large metering quantity, the maximum working length of the Geneva wheel is designed as $200 \mathrm{~mm}$.

\subsubsection{Groove Cross-Section Shape and Slot Number}

The groove cross-section shape has an important influence on seed filling and metering. The cross-section area must be in line with the requirements of metering quantity. The Groove in the paper adopts arc-shaped cross section in order to carry out seed filling or metering. When metering small seeds, the trench should be shallow, and the slot number should be more, and metering quantity is small and uniform. When metering big seeds, in order to reduce the damage to seed, so the groove radius must be augmented and the depth of the slot should be decreased and no less than half the thickness of the seed.

Groove radius and slot number were determined based on the literature recommended value, Geneva wheel dimension, seed dimension and groove teeth strength. Groove radius is $6.5 \mathrm{~cm}$ and slot number is 10. The major technique parameters of the Geneva device are shown in Table 1.

\section{Calculation of Metering Quantity}

\subsection{Basic Physical Properties of Grass Seed}

Grass seeds belong to the category of agricultural seeds, has the same characteristics with agricultural seeds. But there is great difference between agricultural seeds and grass seeds. Grass seed particles are smaller, and the yield is lower. The physical properties of grass seeds have an important influence on the design of the main structure parameters of the seeder and setting of the planting parameters. The relevant physical parameters of grass seeds including: morphological characteristics, mass of 1000-grain, density, volume density, neatness, moisture content, viability, germination rate, repose angle, sliding friction angle and internal friction angle [15]. In the paper, some typical physical properties such as morphological characteristics, mass of 1000-grain and volume density were measured (Table 2).

As seen in Table 2, the dimensions, mass of 1000 -grain and volume density vary with the variety of seeds.

\subsection{Metering Quantity Calculation}

The relationship between metering quantity per hectare $m$ and the effective length of the corresponding Geneva wheel $L$ is as follows:

$$
m=\gamma \times N \times S \times L \times R
$$

where, $N$-slot number of metering device;

$S$-cross-sectional area of a single tank of metering device;

$L$ - the effective length of the Geneva wheel;

$R$ - the metering device rotating revolutions per hectare, $R=\frac{10000}{3 \pi d i}$.

Table 1 Structure parameters of the grooved gearing equipment.

\begin{tabular}{ll}
\hline Parameters & Value \\
\hline Geneva wheel diameter $/ \mathrm{mm}$ & 100 \\
Slot number & 10 \\
Groove radius $/ \mathrm{mm}$ & 6.5 \\
Each slot cross-section area $/ \mathrm{mm}^{2}$ & 400 \\
Valid working length $/ \mathrm{mm}$ & 200 \\
\hline
\end{tabular}

Table 2 Basic physical characteristic parameters of several kinds of grass seed.

\begin{tabular}{|c|c|c|c|c|c|}
\hline \multirow{2}{*}{ Variety } & \multicolumn{3}{|c|}{ Seed dimensions $/ \mathrm{mm}$} & \multirow{2}{*}{$\begin{array}{l}\text { Mass of } \\
1,000 \text {-grain/g }\end{array}$} & \multirow{2}{*}{ Volume density $/ \mathrm{g} \cdot \mathrm{cm}^{-3}$} \\
\hline & Length & Width & Thickness & & \\
\hline Alfalfa & 2.6 & 1.4 & 0.8 & 1.95 & 0.75 \\
\hline Astragalus adsurbens Pall cv & 1.6 & 1.3 & 0.7 & 1.8 & \\
\hline Elymus & $\sim 6$ & & & 3.2 & \\
\hline Rapeseed & 1.2 & 1.2 & 1.1 & 3.74 & 0.72 \\
\hline
\end{tabular}


$m$-Planting quality per hectare;

$\gamma$-Volume density;

$d$-The ground wheel diameter, $d=0.65 \mathrm{~m}$;

$i$ - The transmission ratio of the ground wheel and metering wheel, $i=\frac{50}{17}$.

Based on Table 2 and according to the Eq. 1, the length of metering device Geneva wheel was calculated by being programmed in the Matlab language. When planting small seeds, $N$ is 20 . And when planting big seeds, $N$ is 10 . Metering quantity of the pneumatic conveying type metering device was get and shown in Tables 3 and 4. And then the working length scale value of Geneva wheel per hectare can be seen clearly. According to the scale of the metering device (Fig. 7), the metering quantity can be adjusted. The volume density of grass-seed was shown in Table 5.

Table 3 Seeding rate table of pneumatic conveyed seed metering device (big seeds).

\begin{tabular}{|c|c|c|c|c|c|c|c|c|c|}
\hline \multirow{2}{*}{$\begin{array}{l}\text { Working length } \\
\text { scale value of } \\
\text { Geneva wheel }\end{array}$} & \multicolumn{9}{|c|}{ Metering quantity } \\
\hline & Wheat & Barley & Rye & Oat & Beans & Pea & Corn & Flax & Grass seed \\
\hline 10 & 18 & 15 & 18 & 8 & & & & 15 & 8 \\
\hline 20 & 39 & 33 & 39 & 18 & 30 & 20 & 33 & 33 & 22 \\
\hline 30 & 59 & 50 & 60 & 28 & 55 & 51 & 63 & 40 & 37 \\
\hline 40 & 79 & 70 & 81 & 40 & 80 & 76 & 72 & 66 & 51 \\
\hline 50 & 100 & 89 & 102 & 50 & 100 & 96 & 91 & 82 & 64 \\
\hline 60 & 119 & 100 & 123 & 64 & 121 & 117 & 111 & 99 & \\
\hline 70 & 139 & 120 & 143 & 78 & 142 & 136 & 131 & 115 & \\
\hline 80 & 158 & 144 & 164 & 91 & 163 & 150 & 151 & 132 & \\
\hline 90 & 178 & 152 & 185 & 104 & 184 & 190 & & 148 & \\
\hline 100 & 198 & 180 & 205 & 110 & 206 & 200 & & 154 & \\
\hline 110 & 218 & 198 & 228 & 130 & 228 & 221 & & 180 & \\
\hline 120 & 239 & 210 & 247 & 142 & 250 & 242 & & 196 & \\
\hline 130 & 260 & 234 & 268 & 154 & 273 & 263 & & & \\
\hline 140 & 279 & 252 & 288 & 166 & 295 & 284 & & & \\
\hline 150 & 300 & 271 & 309 & 176 & 318 & 305 & & & \\
\hline 160 & 318 & 290 & 320 & 190 & 339 & 326 & & & \\
\hline 170 & 339 & 309 & 350 & 202 & 360 & 347 & & & \\
\hline 180 & 359 & 326 & 370 & 215 & 381 & 300 & & & \\
\hline 190 & & & & & 402 & 391 & & & \\
\hline 200 & & & & & 424 & 412 & & & \\
\hline
\end{tabular}

Table 4 Seeding rate table of pneumatic conveyed seed metering device (small seeds).

$\mathrm{kg} / \mathrm{hm}^{2}$

\begin{tabular}{lllll}
\hline Working length scale & Metering quantity & & \\
\cline { 2 - 5 } value of Geneva wheel & Rape & Grass seed & Lucerne & Alfalfa/Medicago sativa \\
\hline 2.5 & 1.0 & 0.8 & 1.2 & 1.0 \\
5 & 2.3 & 1.7 & 2.0 & 2.0 \\
10 & 4.0 & 3.6 & 6.2 & 5.0 \\
15 & 7.4 & 5.8 & 9.4 & 9.0 \\
20 & 10.1 & 8.0 & 12.8 & 12.0 \\
25 & 12.5 & 10.1 & 15.8 & 15.1 \\
30 & 15.2 & 12.2 & 18.9 & 18.2 \\
\hline
\end{tabular}


Table 4 continued

\begin{tabular}{lllll}
\hline Working length scale & Metering quantity & & & Alfalfa/Medicago sativa \\
\cline { 2 - 5 } value of Geneva wheel & Rape & Grass seed & Lucerne & 21.3 \\
\hline 35 & 17.6 & 14.3 & 22.1 & 24.3 \\
40 & 20.3 & 16.5 & 25.3 & \\
45 & & 18.6 & & \\
50 & & 20.7 & \\
55 & & 22.8 & \\
60 & & 25.0 & \\
65 & & 27.1 & \\
70 & & 29.2 & & \\
\hline
\end{tabular}

Table 5 Volume density of grass-seed.

\begin{tabular}{lllllllllllll}
\hline Name & Wheat & Barley & Rye & Oat & Beans & Pea & Corn & Flax & $\begin{array}{l}\text { Grass } \\
\text { seed }\end{array}$ & Rape & Lucerne & $\begin{array}{l}\text { Alfalfa/Medic } \\
\text { ago sativa }\end{array}$ \\
\hline Bulk density $\mathrm{g} \mathrm{cm}^{-3}$ & 0.78 & 0.68 & 0.80 & 0.53 & 0.82 & 0.80 & 0.80 & 0.72 & 0.36 & 0.65 & 0.75 & 0.75 \\
\hline
\end{tabular}

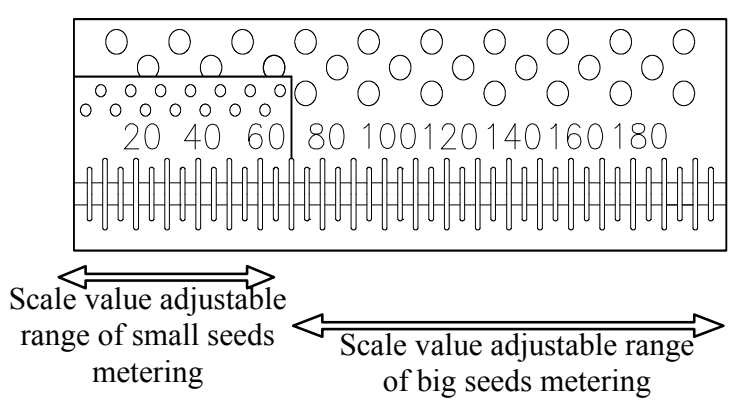

Fig. 7 Working length scale of metering device Geneva wheel.

\section{Metering Device Performance Test}

In order to verify the working performance of the metering device, the experiment on Alfalfa was carried out on the seeder test-bed. The metering quantity was checked on different scale value of Geneva wheel working length. The working width is 3 $\mathrm{m}$, and the ground wheel diameter is $0.65 \mathrm{~m}$, and the ground wheel revolves 19 rounds. The experiment was repeated three times on the same value of working length scale, and the test data were shown in Table 6.

Seen from the data listed in Table 6 , there are some errors in the metering quantity of the metering device when the working length scale value of the Geneva wheel is the same, and the error is less than or equal to $5 \%$. It is caused mainly due to the physical characteristics, humidity, friction between seeds, and
Table 6 Sowing rate of Alfalfa under different working length scale of metering device Geneva wheel.

\begin{tabular}{lllll}
\hline \multirow{2}{*}{ Scale value } & \multicolumn{4}{c}{ Metering quantity $/ \mathrm{kg} \cdot \mathrm{hm}^{-2}$} \\
\cline { 2 - 5 } & 1 & 2 & 3 & Average \\
\hline 2.5 & 0.8 & 1.2 & 1.1 & 1.03 \\
20 & 12.3 & 11.5 & 12.1 & 11.97 \\
40 & 24.5 & 25 & 25.5 & 25 \\
\hline
\end{tabular}

friction between seeds and seed can wall which influence the fluidity of the seeds.

\section{Conclusions}

A kind of central outside Geneva wheel metering equipment which can match with pneumatic conveying type metering device was designed. Through adjusting the Geneva mechanism, the metering device can meter both small seeds and big seeds, and also meter seeds with good fluidity or poor fluidity. Based on the different physical characteristics of different kinds of seeds, the metering quantity of pneumatic conveying type metering device was calculated, and the working length scale corresponded to the metering quantity. And then the working performance of the metering device was tested by the experiment on Alfalfa. The error in the metering quantity of the metering device when the working length scale value of the Geneva wheel is the same is less than or equal to $5 \%$. 


\section{Acknowledgements}

The article is published with funding support from the application promotion and demonstration of TRIZ in Inner Mongolia, China, and the project number is 2013IM020800.

\section{Reference}

[1] Chang, J. L., Zhang, X. H., and Chen, Y. Q. 2007. "Design of the Quantitative Force Feed in the Air-Stream Central-Type Drill System." Journal of Agricultural Mechanization Research 6: 66-8.

[2] Chinese Academy of Agricultural Mechanization Sciences. 2007. Agricultural Machinery Designing Handbook, Volume 1. Peking: China's Agricultural Science and Technology Press.

[3] Bansal, R. K., Gharras, O. E., and Hamilton, J. H. 1989. "A Roller-Type Positive-Feed Mechanism for Seed Metering." Journal of Agricultural Engineering Research 43: 28-31.

[4] Singh, R. C., Singh, G., and Saraswat, D. C. 2005. "Optimization of Design and Operational Parameters of a Pneumatic Seed Metering Device for Planting Cottonseeds." Biosystem Engineering 92 (4): 429-38.

[5] Bereket, B. Z. 2004. "Effect of Different Operating Parameters on Seed Holding in the Single Seed Metering Unit of a Pneumatic Planter." Turkish Journal of Agricultural Machinery 28 (6): 435-41.

[6] Orth, R. J., Marion, S. R., and Granger, S. 2009. "Evaluation of a Mechanical Seed Planter for Transplanting Zostera Marina (Eelgrass) Seeds." Aquatic Botany 90: 204-8.

[7] Liao, Q. X., Zhang, M., and Yu, J. J. 2011. "Pneumatic
Centralized Metering Device for Rapeseed." Transactions of the Chinese Society for Agricultural Machinery 42 (8): 30-4.

[8] Qi, B., Zhang, D. X., and Cui, T. 2013. "Design and Experiment of Centralized Pneumatic Seed Metering Device for Maize." Transactions of the Chinese Society of Agricultural Engineering (Transactions of the CSAE) 29 (18): 8-15.

[9] Qi, B., Zhang, D. X., Liu, Q. W., Yang, L., Shi, S., and Cui, T. 2015. "Design and Experiment of Cleaning Performance in a Centralized Pneumatic Metering Device for Maize." Transactions of the Chinese Society of Agricultural Engineering (Transactions of the CSAE) 31 (1): 20-7.

[10] Qi, B., Zhang, D. X, and Cui, T. 2013. "Design and Experiment of Centralized Pneumatic Seed Metering Device for Maize." Transactions of the CSAE 29 (18): 8-15.

[11] He, J. L., and Qiu, Z. R. 2001. "Experimental Study on a New Type Seed Meter." Transactions of the CSAE 17 (2): 80-3.

[12] Wang, Z. H. 2014. "Optimizing and Experiment of the Key Parts of the Air Seeder.” Ph.D. thesis, Peking: China Agricultural University.

[13] Li, Z. H., Wang, D. C., and Liu, G. L. 2009. "Experimental Study on Sowing Seeds by Air-Stream Metering Mechanism." Transactions of the CSAE 25 (1): 89-93.

[14] Li, Z. H., Wang, D. C., and Liu, G. L. 2009. "CFD Simulation and Improvement of Air-Stream Distributive Metering Device." Transactions of the Chinese Society for Agricultural Machinery 40 (3): 64-8.

[15] Wang, Q. X. 2013. "Process Selection and Technology Study on Rape-Seed Pelleting." Ph.D. thesis, Peking: China Agricultural University. 